\title{
Acute effects of vibration from a chipping hammer and a grinder on the hand-arm system
}

\author{
Steve Kihlberg, Monica Attebrant, Gösta Gemne, Anders Kjellberg
}

\begin{abstract}
Objectives-The purpose of this study was to compare various effects on the hand-arm system of vibration exposure from a chipping hammer and a grinder with the same frequency weighted acceleration. Grip and push forces were measured and monitored during the exposure. The various effects were: muscle activity (measured with surface electrodes), discomfort ratings for different parts of the hand-arm system (made during and after exposure), and vibration perception threshold (for 10 minutes before and 10 minutes after the exposure).

Results-No increase in muscle activity due to exposure to vibration was found in the hand muscle studied. In the forearm, conversely, there was an increase in both muscles studied. For the upper arm the muscle activity only increased when exposed to impact vibration. Subjective ratings in the hand and shift in vibration perception threshold were effected more by the grinder than the hammer exposure.

Conclusion-These results show that the reaction of the hand-arm system to vibration varies with frequency quantitatively as well as qualitatively. They do not support the notion that one single frequency weighted curve would be valid for the different health effects of hand-arm vibration (vascular, musculoskeletal, neurological, and psychophysiological).
\end{abstract}

Division of Work and Environmental Physiology S Kihlberg

Division of Applied Work Physiology

M Attebrant

Division of

Occupational

Medicine

G Gemne

Division of

Psychophysiology,

National Institute of

Occupational Health,

S-171 84, Solna,

Sweden

A Kjellberg

Correspondence to:

Dr S Kihlberg, Division of

Work and Environmental

Physiology, National

Institute of Occupational

Institute of Occupational

Sweden.

Accepted 19 June 1995
(Occup Environ Med 1995;52:731-737)

Keywords: electromyography; hand-arm vibration; mechanical shocks; vibration perception

Assessment of exposure to impact vibration has been a subject of discussion from the time of publication of the international standard for measurement and assessment of hand-arm vibration, ISO 5349. ${ }^{1}$ The standard stated that the method could, to start with, be used for exposure to both impact and non-impact vibrations. The correctness of this statement can only be confirmed in epidemiological investigations of health hazards; so far, no such study has been carried out. Data from studies on the prevalence of vibration white finger (VWF) also seem to challenge the statement.
High impulse acceleration not accounted for by the ISO weighted curve was proposed by Starck to contribute to the high prevalence of Raynaud's phenomenon in a group of pedestal grinders. ${ }^{2}$ Other investigators suggested that the large number of frequencies outside the range of the ISO weighted curve (well above $1 \mathrm{kHz}$ ) might have contributed to the prevalence of VWF found in workers who used impact tools (riveting hammer). ${ }^{34}$ Other studies found no differences between exposures to impact and harmonic vibration in either acute effects or prevalence of VWF. ${ }^{56}$ Recent laboratory studies indicated that different grip and push forces have a large impact on the acute effects on the hand-arm system. ${ }^{78}$ Different tools require different strengths of grip and push forces to operate properly. An impact drill requires a higher push force than does a drill hammer. At the same vibration of the two tools, the impact drill would cause a higher transmission of vibration to the handarm system.

To obtain better knowledge about the qualitative and quantitative relations between the frequency weighted curves and various health hazards induced by vibration is a matter of major importance. A project has been carried out that studied various acute effects on man of exposure to a grinder (harmonic vibrations) and exposure to a chipping hammer (impact vibrations) with the same frequency weighted acceleration according to ISO 5349. The purpose was to compare the effects of vibration with impact characteristics and vibration with harmonic characteristics on: (a) muscular activity in the hand and arm; (b) perceived discomfort; (c) vibration perception threshold shift on the dorsum of the hand.

\section{Method}

Three test series were performed concerning: (a) muscular activities, (b) shifts in vibration perception threshold, and (c) subjective ratings during exposure to two commonly used hand held powered tools. The two tools were a chipping hammer and a grinder with notably different vibration characteristics: different types of vibration (impact vibration from the chipping hammer and harmonic vibration from the grinder), and different fundamental frequencies $(50 \mathrm{~Hz}$ and $137 \mathrm{~Hz}$, respectively, fig 1). Both exposures had a frequency weighted acceleration of $8 \mathrm{~m} / \mathrm{s}^{2}$ according to ISO 5349. The two tools were simulated with an electrodynamic vibrator (Brüel and Kjaer $4805+4812$ ) equipped with a special handle where both grip and push forces could be measured and monitored (fig 2). 
Figure $11 / 3$ Octave band spectra of the chipping hammer and grinder exposures used.

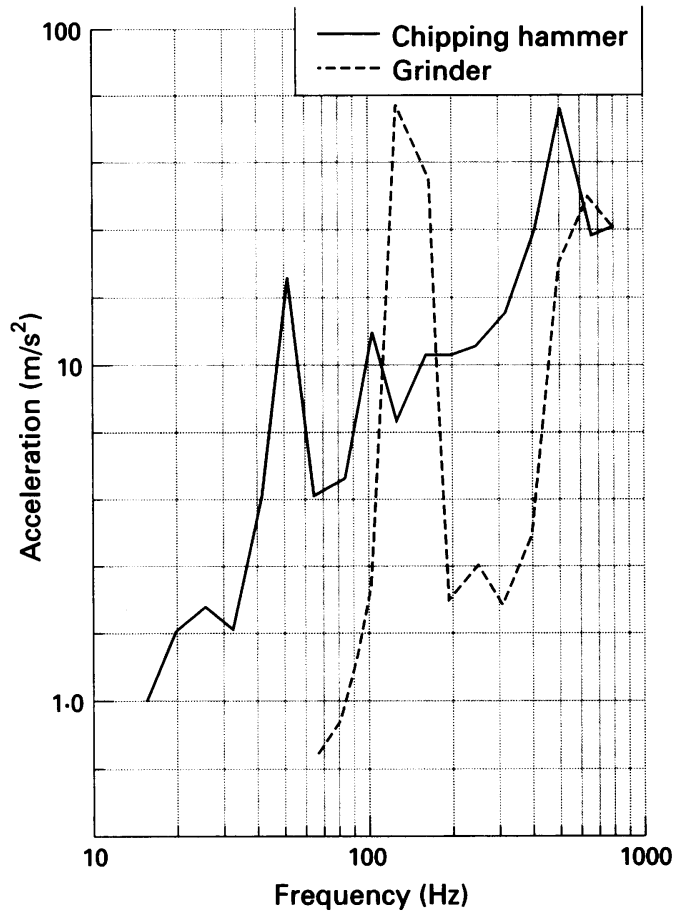

SUBJECTS AND TEST SET UP

Fifteen healthy men, who had not been occupationally or otherwise regularly exposed to vibration, participated in the studies. There were no signs of neurological or other disorders among the subjects. The mean age of the subjects was 34 (range 22-58) years, the mean weight was $75(63-85) \mathrm{kg}$, and the mean stature was $178(171-192) \mathrm{cm}$.

The subject held his upper arm almost vertically, with an elbow angle of about $110^{\circ}$ during the tests (fig 2). The direction of excitation was along the forearm. Both the push and grip forces were about $30 \mathrm{~N}$ during all three test series to avoid fatigue. The forces were monitored by two analog devices mounted on the wall in front of the subjects and the subjects

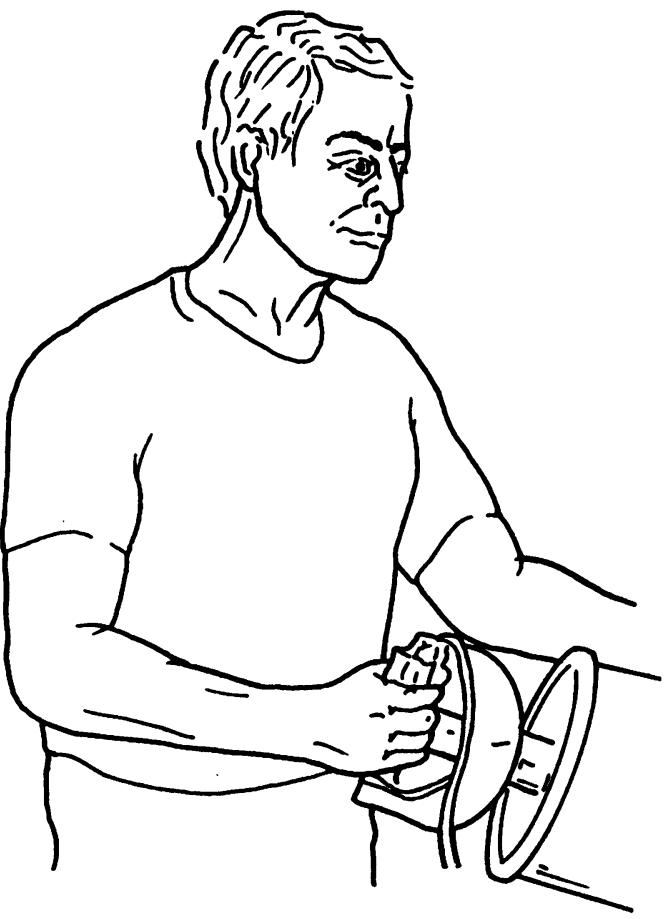

were asked to keep the pointers within a specified area during the test. The subject trained for the task before the actual test, especially to be able to keep an eye on the two pointers at the same time.

\section{MUSCLE ACTIVITY}

The muscular activity was measured by electromyography with surface electrodes (Medicotest). Four muscles in the right hand and arm were studied: hand (interosseus dorsalis I), forearm flexor (flexor carpi ulnaris), forearm extensor (extensor carpi radialis), and upper arm (triceps brachii).

The muscular activity was compared with a reference voluntary electrical activation recorded for 10 seconds each. The reference activities were chosen to give an adequate electromyography signal. The reference voluntary electrical activity for the interosseus muscle was recorded at a steady palmar flexion of the index finger with a force of $10 \mathrm{~N}$ against a sling around the distal phalanx. The hand and arm were resting on a table with the fingers outside the edge of the table. The reference voluntary electrical activity for the forearm muscles was recorded during a steady contraction at a grip force of $85 \mathrm{~N}$ exerted on the test handle with the arm in the same position as in the test. For the triceps muscle the subject was standing erect with his right arm resting on a support at the elbow with an elbow angle of 90 degrees. From that position the reference voluntary electrical activity was recorded during an extension of the forearm with a force of $50 \mathrm{~N}$ against a sling around the wrist.

The muscle activity was recorded during the two types of vibration exposure and a static exposure without vibration, but with the same grip and push forces as during vibration. Each exposure was repeated six times and recorded for 20 seconds. The three exposures were rotated between the subjects with rest periods of four minutes in between to avoid fatigue.

The amplitude of the recorded electromyographic signal was full wave rectified and low pass $(800 \mathrm{~Hz})$ and high pass $(20 \mathrm{~Hz})$ filtered and integrated with an integrating time of $50 \mathrm{~ms}$. The signal was sampled at $2 \mathrm{kHz}$ and stored in a frequency analyser (Brüel and Kjaer 2032). The amplitude probability distribution function (APDF, Jonsson 1982) was calculated with the help of the frequency analyser to express the activity distribution during the different exposures. ${ }^{9}$ The median muscle activities for the three exposures (static, grinder, and chipping hammer) were then compared. The frequency analyser was also used to control the electromyographic signal for noise and artefacts. In such a control one of the subjects had to be excluded due to poor quality of the electromyographic signals.

\section{SUBJECTIVE RATINGS}

Ratings of discomfort and other subjective qualities were collected after 30 seconds and after an additional 110 seconds of a three minute long exposure to the two types of vibration and the static exposure, as well as 
every minute during a five minute period after the exposure. Separate ratings were made of the discomfort felt in the hand, forearm, and upper arm. The three experimental sessions (static, grinder, and chipping hammer) were carried out on separate days with the condition order rotated.

Discomfort was rated on a 20 point scale with verbal labels at seven of the points. To get a qualitative description of the subjective effects of the two types of vibration six additional scales were used. These scales were based upon a pilot study in which factor analyses were made of ratings of different types of vibrations on rating scales, which all consisted of an adjective and a five point rating scale (from not at all to very much). These analyses yielded a three factor solution for ratings made both during and after exposure. Each factor was represented by two or three scales, and factor scores were computed as means of ratings on these scales. The three factor scores computed from the ratings made during exposure were labelled pricking (mean of ratings on two scales: pricking, tickling), piercing (piercing, insensitising) and jerky (jerky, hard, shaky). The scales used for describing the feelings after the exposure were called pricking (prickly, itchy, throbbing), warm (warm, cold), and stiff (stiff, numb). Furthermore, pain was rated both during and after exposure with the same type of five point scale. The Swedish adjectives used in the original scales were all common everyday words.

In another test series, overall discomfort ratings were made of the two types of vibration at five levels with $5 \mathrm{~dB}$ intervals $\left(1 \cdot 6-16 \mathrm{~m} / \mathrm{s}^{2}\right)$.

\section{VIBRATION PERCEPTION THRESHOLD}

The assessment of the vibration perception threshold was made with commercially available equipment, Vibrameter (Somedic, Stockholm). ${ }^{10}$ The probe consisted of a massive plastic cylinder with a cross sectional area of $1 \mathrm{~cm}^{2}$. The vibration of the probe was sinusoidal and had a frequency of $100 \mathrm{~Hz}$. The apparatus was mounted in a stand with a pivoting arrangement and was allowed to rest with part of its own weight (about $0.4 \mathrm{~kg}$ ) against the skin. It was placed perpendicularly against the skin above the second metacarpal bone of the dorsum of the right hand at the midpoint between the proximal interphalangeal joint and the carpometacarpal joint. The forearm and the hand rested in an impression of plaster to prevent variation in the position of the probe from one experimental session to another. The temperature of the skin and tissues of the hand was kept stable with an infrared lamp placed about $15 \mathrm{~cm}$ above the hand. The subjects were wearing ear muffs during the experiment to avoid disturbance from irrelevant background noise.

The vibration perception threshold of each subject during recovery after exposure to vibration from the tools was assessed according to the following procedure: (1) The nonvibrating probe was placed against the skin, the intensity of vibration being initially zero. The intensity (expressed as the amplitude of probe displacement) was then slowly increased with constant speed until the subject stated that he perceived vibration. The increase was allowed to continue for about another two seconds, after which intensity began to decrease. The decrease continued until the subject stated that the vibration perception had stopped, and the intensity was then allowed to drop to zero.

(2) For each such measurement cycle (duration 40-60 s), the vibration amplitude at the start of vibration perception was noted as the appearance threshold together with the time when this occurred (in seconds after exposure). When perception stopped the corresponding disappearance threshold was noted. The vibration perception threshold was then determined as the mean of the appearance and disappearance values.

(3) The procedure was then repeated by restarting the measurement cycle as soon as possible after the end of the previous cycle. The repetition continued, with as little delay as possible between cycles; the whole duration of vibration exposure to recovery was 10-15 minutes.

The time it took for one cycle to be completed varied widely because of-for instance, variation in the time when vibration perception appearance and disappearance occurred. This is why the individual observations of thresholds could not be made at precise, predetermined times. Instead, the threshold values at 120,360 , and 600 seconds were measured from a curve fitted to the values at the various measuring times with the method of least squares.

The threshold assessments were made in two different sessions, one for each tool, with a minimum interval of six hours. Each test series started with a pre-exposure perception threshold test for 10 minutes, after which the three minute exposure took place. As soon as possible after the exposure, the threshold was tested for a 10 minute period. The shift in perception threshold was calculated as the percentage difference between the threshold before and after exposure.

\section{DESIGN}

The design of the test series for the muscle activity was a 3 (exposure) $\times 4$ (muscle) factorial design with repeated measurements. The design of the rating test series was a 3 (exposure) $\times 3$ (hand, forearm, upper arm) $\times 2$ (time during exposure) or 5 (time after exposure) factorial design with repeated measurements for the discomfort rating scale. For the other rating scales the design of the rating test series was a 3 (exposure) $\times 3$ (hand, forearm, upper arm) $\times 5$ (time) factorial design with repeated measurements. Models suitable for these designs were used for the analyses of variance. Follow up tests were made with Fisher's least significant difference test. The shifts in vibration perception threshold for the grinder and the chipping hammer were calculated with the functions fitted to the observed values at 120,300 , and 600 seconds and compared by paired Student's $t$ test. 
Figure 3 The muscle activity in percentage of relative voluntary electrical activation (RVE (\%)) for the static, grinder, and chipping hammer exposure. Mean (SEM) of 15 subjects is shown for the muscles, interosseus dorsalis I (hand), flexor carpi ulnaris (forearm flexor), extensor carpi radialis (forearm extensor), and triceps brachii (upper arm).

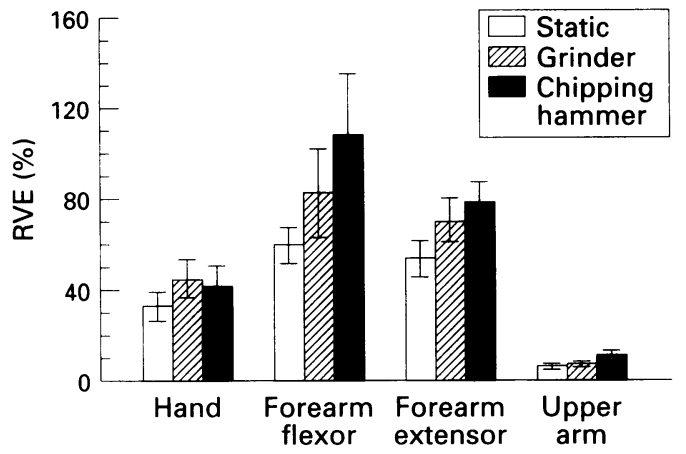

Results

MUSCLE ACTIVITY

There was an interaction between muscles and exposure, for static, grinder, and chipping hammer $(F(6 / 84)=2 \cdot 895, \mathrm{P}<0.02)$. Follow up tests showed that there was a tendency to increased muscle activity due to vibration in
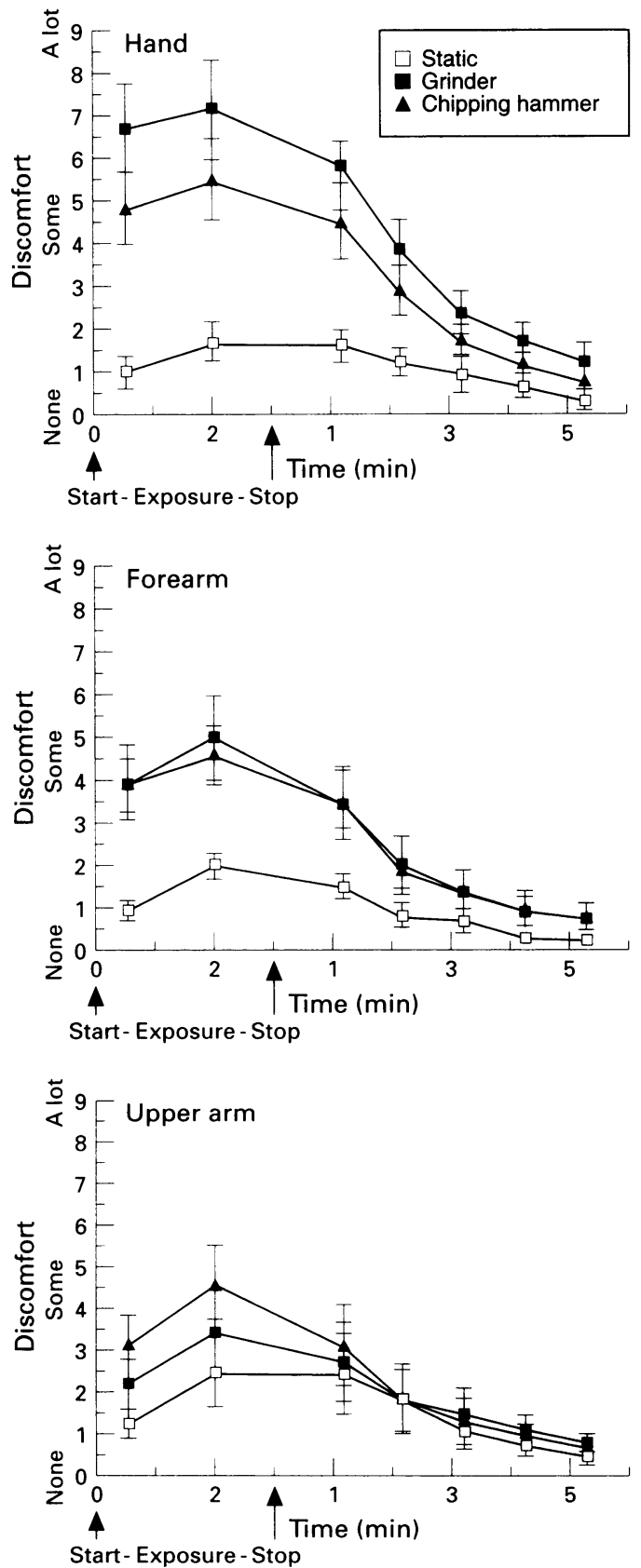

the interosseus muscle $(F(2 / 26)=3.062$, $P>0.06)$. In both the forearm muscles there was an increase in muscle activity when exposed to vibration compared with the static exposure, flexor muscle $(F(2 / 26)=4 \cdot 123$, $\mathrm{P}<0.03)$, and extensor muscle $(F(2 / 26)=$ $11.737, P=0.0002)$. In the extensor muscle the activity during the chipping hammer exposure was insignificantly higher than during the grinder exposure. In the flexor muscle there were significant differences in muscle activity between all three exposures. The muscle activity in the upper arm increased only during the chipping hammer exposure $(F(2 / 26)=12.924, \quad \mathrm{P}=0.0001)$. Figure 3 shows these interactions between exposures and muscles.

\section{SUBJECTIVE RATINGS}

Discomfort during exposure increased from the first to the second rating $(F(1 / 14)=26 \cdot 7$, $\mathrm{P}=0.0001)$. Figure 4 shows that discomfort was rated higher in all parts of the arm during exposure to vibration than during the static exposure $(F(2 / 28)=18 \cdot 16, \mathrm{P}=0.0001)$. There were also consistent differences between the two vibration exposure conditions. Thus, grinder vibration yielded higher discomfort ratings than the chipping hammer vibration in the hand, whereas the opposite applied to the upper arm. This was supported by the analysis of variance, which showed a significant interaction between exposure and part of the arm $(F(2 / 28)=7 \cdot 55, \mathrm{P}=0.003)$.

The discomfort ratings made after exposure showed a general decline to very low ratings after five minutes $(F(4 / 56)=40 \cdot 85), P=$ $0.0001)$. The ratings of discomfort in the hand in the vibration exposure were significantly higher than the static exposure ratings during the first five minutes $(F(2 / 28)=14 \cdot 1, P=$ $0.0001)$, and there was a tendency $(F(1 / 14)=$ $3.75, P=0.07)$ for the grinder vibration to give stronger effects after the exposure than the chipping hammer vibration did (fig 5). In the forearm, the exposure conditions yielded virtually identical ratings, although both were higher than in the control condition. The ratings of discomfort in the upper arm showed no differences between types of vibration.

The grinder vibration was rated as having more pricking $(F(1 / 14)=6.69, \quad \mathrm{P}=0.03)$,

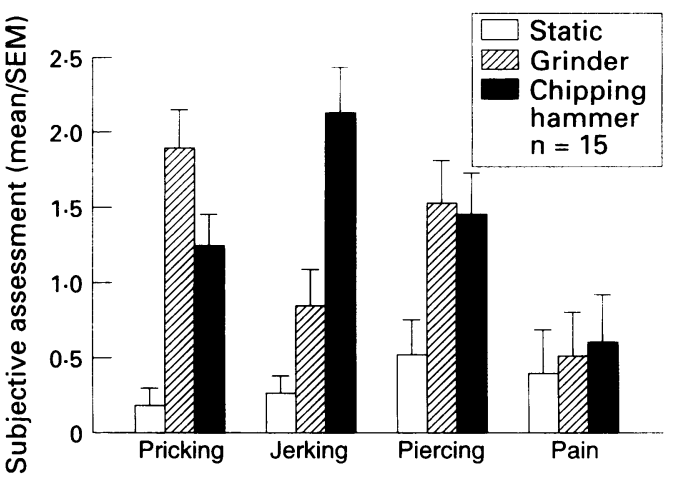

Figure 5 Subjective rating of pricking, jerking, piercing, and pain during static, grinder, and chipping hammer exposures. Mean (SEM) of 15 subjects is shown. 
Figure 6 Subjective rating of pricking and stiffness as a function of time after static, grinder and chipping hammer exposures. Mean (SEM) each point. of 15 subjects are shown for
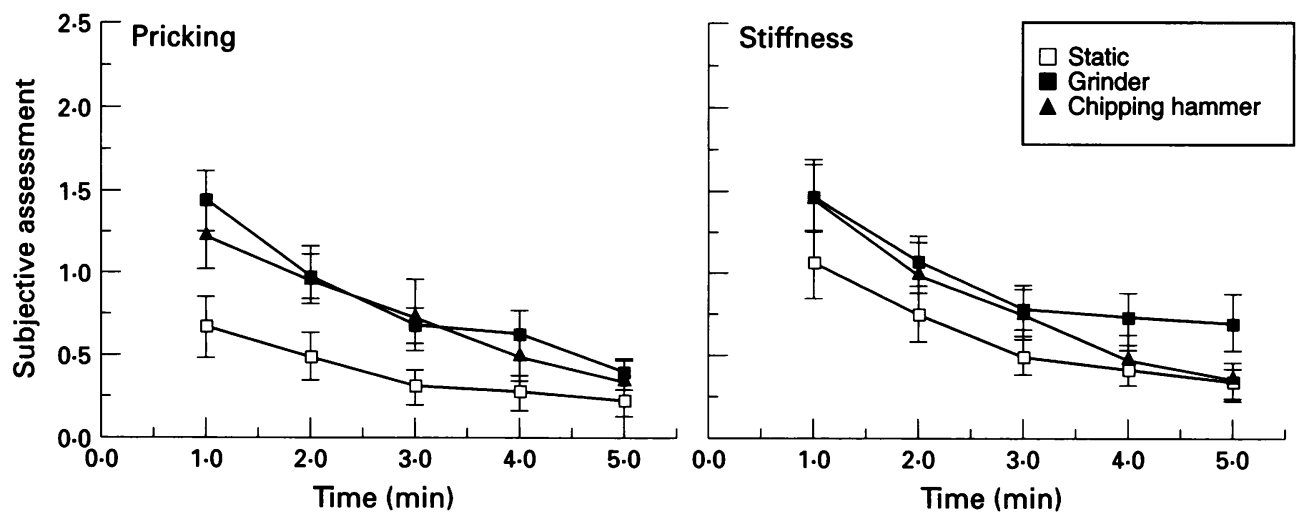

equal piercing, and less jerking $(F(1 / 14)=$ $42 \cdot 66, P=0 \cdot 0001)$ than the impact vibration during exposure (fig 5). In all these factor scores, both vibration exposures were given significantly higher ratings than the static exposure. This was not the case for the pain ratings, which were about 0.5 in all three conditions.

After exposure the effects rated with the factor scores pricking, warmth, stiffness, and pain, showed no differences between the vibration exposure conditions. Only the stiffness and pricking scores were higher in the vibration exposures than the static exposure $(F(2 / 28)=10.66 \mathrm{P}=0.0004, F(2 / 28)=3.94$ $\mathrm{P}=0.031$, respectively, fig 6 ).

\section{VIBRATION PERCEPTION THRESHOLD}

The effect of vibration exposure from both tools was a threshold increase followed by a steady recovery of perception lasting for 10 minutes or more, as seen in the example from one subject (fig 7).

The rise in vibration perception threshold caused by exposure to grinder vibration was generally twice that of the chipping hammer exposure. Figure 8 shows that the difference in rises in vibration perception threshold between the two exposures was significant at 120 seconds after stimulation $(341 \%$ and $149 \%$ respectively; $t=2 \cdot 23, \mathrm{P}<0.05)$, nonsignificant at 300 seconds, and again significant at 600 seconds $(78 \%$ and $35 \%$, respectively; $t=2 \cdot 63, \mathrm{P}<0.05$ ).

Figure 7 Example from one subject of vibration perception before and directly after exposure as a function of time.

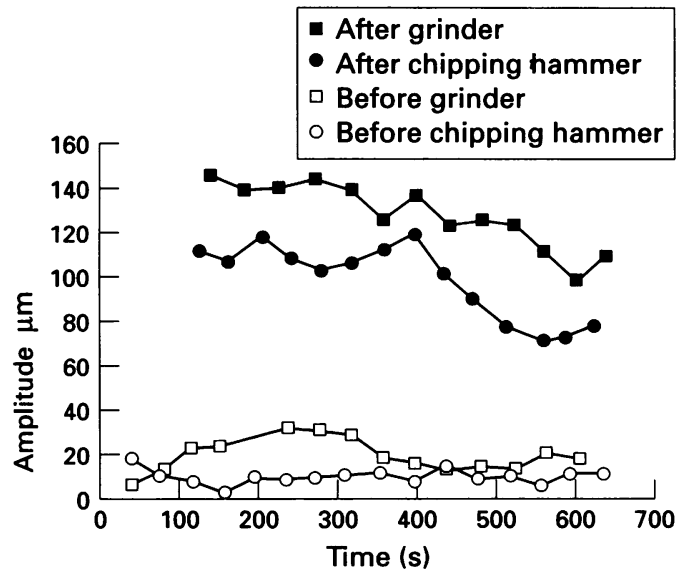

\section{Discussion}

The extent to which movements of the joints occur that are induced by vibration depends on the characteristics of the transmission of vibration in the hand-arm system. ${ }^{8}$

Frequencies $<50 \mathrm{~Hz}$ are transmitted unattenuated to the elbow, whereas frequencies $>100 \mathrm{~Hz}$ are attenuated already at the wrist. The acute effects of vibration found in the present study therefore reflect the differences in fundamental frequencies $(50 \mathrm{~Hz}$ and $137 \mathrm{~Hz}$ ) of the tools under investigation. Because of these differences, the results cannot be used for general conclusions about impact $v$ nonimpact vibration. They do contribute, however, to the knowledge about vibrational effects of two commonly used tools that represent two basic types of vibration (impact and harmonic). Impact tools usually have fundamental frequencies of $20-60 \mathrm{~Hz}$, the frequencies of grinders are $100-400 \mathrm{~Hz}$.

\section{MUSCLE ACTIVITY}

The increase in electromyographic activity when exposed to vibration reflects the well known tonic vibration reflex of a muscle, and possibly other mechanisms dependent on neuromuscular vibration. ${ }^{11} 12$ The differences in electromyographic activity between the two vibration exposures found in the forearm flexor and triceps muscles could be explained by the differences in transmission of the vibration through the hand and along the arm. In another experiment performed under the same

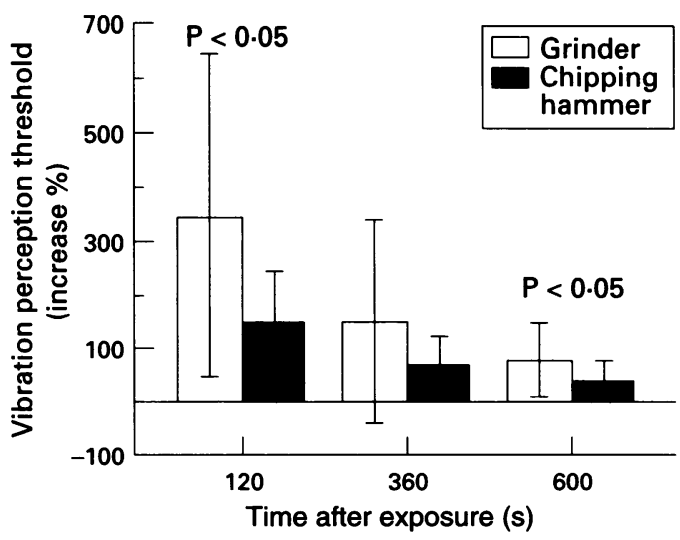

Figure 8 Increase in vibration perception threshold after three minutes of exposure to grinder and chipping hammer at 120,360 , and 600 seconds after the exposure. Mean (SD) of 14 subjects is shown. 
conditions an impact exposure with a fundamental frequency of $50 \mathrm{~Hz}$ was found to be transmitted almost without attenuation to the elbow. ${ }^{8}$ A grinder exposure with a fundamental frequency of $137 \mathrm{~Hz}$ was in the same study attenuated by about $20 \mathrm{~dB}$ at the wrist and therefore should have less influence than the grinder on the muscle activity in the arm. During the impact exposure, the triceps muscle would thus be more affected than during the grinder exposure.

There were no significant differences in activity of the extensor muscle between the two vibration exposures. The discrepancy in results between the flexor muscle and the extensor muscles may depend on the large variation in muscle activity between subjects, depending on how they stabilise the wrist for the impulse forces caused by the chipping hammer. If the subjects hold their wrist in the neutral position, there will be an extension force acting on the wrist at every impact, and because of a stretch reflex the activity in the flexor muscle will be higher than in the extensor muscle.

\section{SUBJECTIVE RATINGS}

Discomfort in the hand was rated higher during exposure to grinder vibration, than during exposure to chipping hammer vibration. In the forearm, there was no difference between the two exposures, whereas discomfort in the upper arm was rated higher for the chipping hammer. These differences in discomfort ratings between different parts of the hand-arm system could depend on different fundamental frequencies of the two exposures and the shape of the transfer function of the hand-arm system. Although there was no relation between discomfort ratings and muscle activity in the hand and forearm, in the upper arm impact exposure produced both higher discomfort ratings and higher muscle activity. The fact that the muscle activity in the triceps muscle was low indicates, however, that the discomfort ratings probably did not originate from muscle activity.

\section{VIBRATION PERCEPTION THRESHOLD}

The strong effect on the vibration threshold and perception of the grinder vibration may be an indication that nerve functions in the handarm system (particularly the hand) would be more at risk after grinder vibration than after chipping hammer vibration.

The vibration perception threshold depends on test frequency, as has been shown for instance by Lamoré and Keemink, Harada and Griffin, and Lundström et al. ${ }^{13-15}$ This frequency dependency has also been found to depend on probe size and probe surroundings. ${ }^{16}$ The shape of the threshold curve also varies depending on whether the vibration is expressed as displacement, velocity, or acceleration..$^{1314}$ The differences in perception threshold over the frequency range could also play an important part in the effects measured after exposure to vibrations with different fundamental frequencies.

Maeda and Griffin found differences in temporary threshold shift in vibrotactile per- ception after exposure for five minutes to repetitive shocks with the same frequency weighted root mean squares $(2 \cdot 5,5$, or 10 $\mathrm{m} / \mathrm{s}^{2}$ ) but with different rates of shock repetition. ${ }^{17}$ They used one period of $100 \mathrm{~Hz}$ as the shock and repeated it 5, 25, 50, and 100 times a second. The temporary threshold shift measured at the fingertip with a stimulus frequency of $125 \mathrm{~Hz}$, increased with frequency of shock repetition. The highest temporary shift in threshold was found for the continuous 100 $\mathrm{Hz}$ frequency. Frequency spectra (octave or $1 / 3$ octave) for the four exposures broadened with decreasing shock frequency. This might indicate that man is more sensitive to a pure tone of vibration than to random vibration or vibration containing several frequencies, as is the case for noise. ${ }^{1819}$ An alternative explanation is that the difference in excitation frequency $(5,25,50$, and $100 \mathrm{~Hz})$ and test frequency are reflected in the results. The results found by Maeda and Griffin coincide with the results found in the present studythat is, a higher shift in threshold after the grinder exposure (at $137 \mathrm{~Hz}$ ) than after the chipping hammer exposure (at $50 \mathrm{~Hz}$ ) with a test frequency of $100 \mathrm{~Hz}$.

The shifts in vibration perception threshold found in the present study also harmonise with the results of the discomfort ratings tests, with higher discomfort rating scores in the hand and larger shifts for the grinder than for the impact vibration exposure.

\section{IMPACT $v$ HARMONIC VIBRATION}

The differences in acute effect between exposures to the grinder and chipping hammer found in the present study may be chiefly explained by the difference in the excitation frequency. There is, however, another difference of possible significance between the impact and harmonic exposures, namely the shock wave, pressure wave or elastic wave propagation in the bones in the forearm. ${ }^{8}$ These types of waves have been used by several investigators to study bone characteristics in vivo. ${ }^{20-22}$

In a study of stone quarry workers Sakakibara et al found that duration of vibratory tool operation may correlate with disorders in the right elbow joint but not in the left elbow joint. ${ }^{23}$ The tools they used were chipping hammers and scalers, both impact tools. The difference in exposure between the left and right arms was: no shock waves were transmitted along the left forearm, but never the less, the overall vibration level in the left hand was high because the workers were guiding the tool bit with the left hand.

In a study on 67 foundry workers and a control group of 46 heavy manual workers, Bovenzi et al found that the prevalence of osteoarthritis in the wrist and olecranon spurs in the elbow increased with increasing daily exposure to impact vibration. ${ }^{24}$ They found no correlation between the occurrence of vibration white finger and radiological changes in the arms.

Similar results were found by Burdorf and Monster, with more complaints of pain or 
stiffness of joints among the riveters than among the controls. ${ }^{25}$

Louda et al found seven cases of carpal tunnel syndrome among 23 women exposed to hand-arm shocks from nail or staples air guns. ${ }^{26}$ The frequency weighted accelerations of the air guns were about $1.5 \mathrm{~m} / \mathrm{s}^{2}$ at the highest. These authors proposed that it was the mechanical shocks that overload the hand-arm system. Carlsöö and Mayr measured the acceleration in tool handle, wrist, elbow, and shoulder and calculated the shock loads during work with a pneumatic hammer and a bolt gun. ${ }^{27}$ They found high shock loads in both the wrist and elbow joints and they also found relatively high stretch reflexes in the biceps brachii and the ventral part of the deltoid muscle.

In the future models of how to assess impact vibration should be developed. One way may be to study the shock or pressure waves and try to measure them, or find a method to measure or calculate the impulse they cause.

\section{Conclusion}

Exposures with a predominantly low frequency (around $50 \mathrm{~Hz}$ ) had a greater effect on the arm muscles than exposure with a fundamental frequency of about $137 \mathrm{~Hz}$.

Subjective ratings and vibration perception thresholds shift measurements suggested that the effects on the hands were stronger for the exposure with the fundamental frequency around $137 \mathrm{~Hz}$ than around $50 \mathrm{~Hz}$.

The differences in acute effects from the grinder and the chipping hammer exposure (harmonic and impact vibration) found in this study could mostly be explained by differences in the fundamental frequency of the excitation exposure.

The results of this study do not support the notion that one single frequency weighted curve would be valid for the different health effects of hand-arm vibration (vascular, musculoskeletal, neurological, and psychophysiological).

This study was supported by the Swedish Work Environment Fund.

1 International Standardisation Organisation. Vibration and shock-Guidelines for the measurement and the assessment of human exposure to hand-transmitted vibration. Geneva: ISO, 1984. (ISO 5349.)

2 Starck J. High impulse acceleration levels in hand-held vibratory tools. Scand $f$ Work Environ Health 1984, 10:171-8.

3 Dandanell R, Engström K. Vibration from riveting tools in the frequency range $6 \mathrm{~Hz}-10 \mathrm{MHz}$ and Raynaud's phenomenon. Scand $f$ Work Environ Health 1986 12:338-42.

4 Engström K, Dandanell R. Exposure conditions and Raynaud's phenomenon among riveters in the aircraft industry. Scand F Work Environ Health 1986;12:293-5.

5 Mirbod S, Inaba R. A study on the vibration-dose limit for Japanese workers exposed to hand-arm vibration. Ind Health 1992;30:1-22.

6 Schäfer N, Dupuis H, Hartung E. Acute effects of shocktype vibration to the hand-arm system. Int Arch Occup type vibration to the hand-arm
Environ Health 1984;55:49-59.

7 Hartung E, Dupuis H, Scheffer $M$. Effects of grip and push forces on the acute response of the hand-arm system under vibrating conditions. Int Arch Occup Environ Health 1993;64:463-7.

8 Kihlberg S. Biodynamic response of the hand-arm system to vibration from an impact hammer and a grinder. International fournal of Industrial Ergonomics 1995;16:1-8.

9 Jonsson B. Measurement and evaluation of local muscular strain in the shoulder during constrained work. $f$ Hum Ergol (Tokyo) 1982;11:73-88.

10 Goldberg JM, Lindblom U. Standardised method of determining vibratory perception thresholds for diagnosis and screening in neurological investigation. $f$ Neurol Ncreening in neurological investigation

11 Eklund G, Hagbarth K-E. Normal variability in tonic vibration reflexes in man. Exp Neurol 1966;16:80-92.

12 Martin BJ, Armstrong TJ. Contribution of vibrationinduced alterations of neurosensory mechanisms to tissue stress. In: Gemne $\mathrm{G}$, Brammer AJ, Hagberg $M$ Lundström R, Nilsson T, ed. Stockholm Workshop 94 Hand-arm vibration syndrome. Diagnostics and quantitative relationships to exposure. May 25-29 1994. Stockholm National Institute of Occupational Health 1994:43-4.

13 Lamoré PJJ, Keemink CJ. Evidence for different types of mechanoreceptors from measurements of the psychophysical threshold for vibration under different stimulation conditions. F Acoust Soc Am 1988;83:2339-51.

14 Harada N, Griffin MJ. Factors influencing vibration sense thresholds used to assess occupational exposures to hand thresholds used to assess occupational exposures to han

15 Lundström R, Strömberg T, Lundborg G. Vibrotactile perception threshold measurements for diagnosis of sensory neuropathy. Int Arch Occup Environ Health 1992;64: 201-7.

16 Maeda S, Griffin MJ. A comparision of vibrotactile thresholds on the finger obtained with different equipment. Ergonomics 1994;37:1391-406.

17 Maeda S, Griffin MJ. Temporary threshold shifts in fingertip vibratory sensation from hand transmitted vibration and repetitive shocks. $\mathrm{Br}$ F Ind Med 1993;50:360-7.

18 Landström U, Kjellberg A, Byström M. Acceptable levels of sounds with different spectral characteristics during the performance of a simple and a complex non-auditory task. Fournal of Sound and Vibration 1993;160:533-42.

19 Scharf B, Hellman R. Comparison of various methods for predicting the loudness and acceptability of noise. Part II. Effects of spectral pattern and tonal components. Washington: US Environmental Protection Agency, Office of Noise Abatement Control 1979. (EPA 550/9-79-102.)

20 Chen IIH, Saha S. Wave propagation characteristics in long bones to diagnose osteoporosis. $f$ Biomech 1987;20:523-7.

21 Cheng S, Komi PV, Kyröläinen H, Kim DH, Häkkinen K. In vivo vibrational wave propagation in human tibiae at different ages. Eur f Appl Physiol 1989;59:128-30.

22 Cheng $S$, Timonen J, Suominen $H$. Elastic wave propagation in bone in vivo: methodology. Ergonomics 1995; 28:471-8.

23 Sakakibara H, Suzuki H, Momoi Y, Yamada S. Elbow join disorders in relation to vibration exposure and age in disorders in relation to vibration exposure and age in stone quarry

24 Bovenzi M, Fiorito A, Volpe C. Bone and joint disorders in the upper extremities of chipping and grinding operators. Int Arch Occup Environ Health 1987;59:189-98.

25 Burdorf A, Monster A. Exposure to vibration and selfreported health complaints of riveters in the aircraft industry. Ann Occup Hyg 1991;35:287-98.

26 Louda L, Rousková H, Svoboda L, Muff V. Disease and disorders resulting from hand-arm shocks. In: Dupuis $\mathrm{H}$, Christ E, Sandover J, Taylor W, Okada A, ed 6th International Conference on Hand-Arm Vibration. Bonn: Schriftenreihe des Hauptverbandes der Bown: Schichen Berufsgenossenschaften, 1993:271-7.

27 Carlsöö S, Mayar J. A study of the load on joints and muscles with a pneumatic hammer and a bolt gun. Work Environ Health 1974;11:32-8. 